\title{
Editorial: Industry 4.0 Challenges for Business Process Management and Electronic-Commerce
}

\author{
Bernhard Hitpass ${ }^{1}$ and Hernán Astudillo ${ }^{2}$ \\ ${ }^{1}$ Universidad Técnica Federico Santa María, Informatics Department, Santiago, Chile, bernhard.hitpass@usm.cl \\ 2 Universidad Técnica Federico Santa María, Informatics Department, Santiago, Chile, hernan@inf.utfsm.cl \\ January 2019
}

\section{Introduction}

No one can deny that we are now facing a process of digital transformation transition to digitalization in nearly all the services of our globalized economy. How can this phenomenon be understood from an organizational perspective? The transition to digitalization is not only about switching from paper to the electronic environment, but it also affects the governance of the entire organizational ecosystem. This means that all processes of the value chain should be integrated with IT.

Industry 4.0 denotes the Fourth Industrial Revolution, a term introduced in 2011 at the Hannover Messe, one of the world's largest trade shows, and since then widely used by German industry and government, [2], [4]. Thus, the industrialization stages are:

- Industry 1.0: 1780 - 1870 Steam power.

- Industry 2.0: 1870 - 1950 Chain production, electrical power.

- Industry 3.0: 1950 - 2010 Higher level of automation, digitalization and IT.

- Industry 4.0: 2010 - today Cyber-physical Systems, smart industry, Internet of Things, Big Data, hyperconnectivity.

Business Process Management (BPM) is a systematic approach to identify, map, document, design, implement, measure and control business processes. BPM embraces the increasing IT support to improve, innovate, and manage processes thoroughly, determining business results and creating customer value, achieving thus the business goals with greater flexibility [1].

And of course, Electronic Commerce (e-commerce) refers to managing the purchase, sales, marketing and distribution processes of products and services through internet, with a final vision of executing all commercial operations (transactions) through digital means.

If this new industrial revolution digitalizes all logistic, purchase and sales processes, then e-commerce will account for over $90 \%$ of global commercial transactions [3]. In other words, business process and e-commerce cannot be managed in isolation anymore: behind every service there will be digitalized processes integrated with the entire business participant network.

\section{BPM as Support for Industry 4.0 and E- Commerce}

The new industrial revolution will have a strong impact on the relation of BPM and e-Commerce because it moves manufacturing and production from a centralized to a decentralized paradigm. This will require a widespread adoption of smart interconnection of machinery and systems, not only at the same production site but also across the entire organizational ecosystem. An enormous potential opens up for innovation in business processes and in the way society interacts at a global level.

Unlike our current era, where automated processes already provide real-time operational information, the new industrial cycle will be characterized by a greater:

- $\quad$ Autonomy in the value chain links management,

- Intelligence in the activities or devices responsible for decision making,

- Integration involving all the external agents that interact in the value chain,

- Integration with all the payment services and business transactions, and 
- Transparency from traceability and monitoring in production and logistic systems.

Let's see a scenario that is already partially happening, taken from Schönthaler et al. [5]. Consider a business based on a collaborative business process and integrated with the internet of things (loT); is has smart cyber-physical systems (CPS) devices interconnected with each other and with traditional IT systems, and integrated with loT services. It also has communication channels integrated with all stakeholders, suppliers, business partners, government entities, employers, and distribution and transport logistic systems; and this high level of integration enables and demands independent management of the supply chain.

Thus, for example, records generated by selling processes allow real-time inventory assessment to trigger restocking of parts and materials from suppliers. Purchase orders, invoicing and payments processes can be automated with smart contracts and certificates that use blockchain technology [6], which has gain notoriety by underlying Bitcoin but is quite useful as a tamper-proof high-availability distributed ledger.

Global economies show a growing trend towards integration and standardization of services with their operators. Currently, standardized service offerings in the cloud (cloud services) are enormous and considerably mature, since cloud services are "low-cost and technically simple" [3]. Achieving integration and standardization of services requires as previous stage the standardization of business and organizational processes. The reader might ask: Where is the competition concentrated then? Would a deadly price war be unleashed? The answer again is partly given by Schönthaler et al. [5]: companies do not differ in the standardized services they use, but on how they design and configure their own business processes (see Figure 1). So, the quality of services delivery can be quite different between one competitor and another.

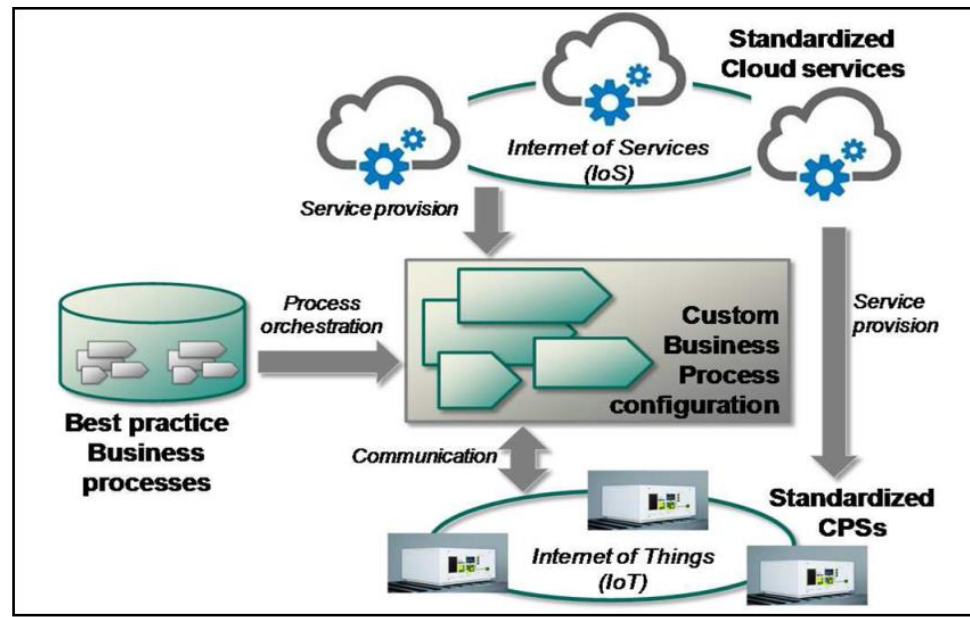

Figure 1: Orchestration of standardized business processes (Source: [5])

Highly competitive organizations will need to develop excellence capabilities for understanding and management of the processes in their value chain, to endow them with a higher degree of intelligence. They will also need to continuously improve business agility, that is, the ability to adapt to changes required or wanted (innovation) through changes in their business processes [4].

A big challenge when integrating the entire value chain, according to the Industry 4.0 concept, is the monitoring of processes' KPI's in real time them into a Corporate Balanced Scorecard that reflects strategic objectives. This is hard because in most organizations, BPMS (BPM Systems) and BI (Business Intelligence) analytical processes operate in isolation, as Vukšić et al. [7] show clearly. There are still big conceptual gaps between business intelligence (BI) more focused on data and process intelligence (BPMS and Process Mining) more focused on control of events.

The increasing speed of smart technology innovation over the last decade will soon allow integrating everything with everyone. The internet is expanding to create a new technological platform to this end, also known as the "Internet of Everything" (loE) [8]. Billions of sensors are being connected to resources, production lines, electricity and distribution networks, logistic networks, homes, offices, stores, vehicles, smart phones, etc. These devices are at the edge of the Internet [9], sitting astride between the world of IT (Information Technologies) and the world of devices and OT (Operational Technologies).

The construction, maintenance and operation of the Industry 4.0 ecosystem raises huge challenges, but e-commerce brings to the table tools and techniques that allow to exploit a key aspect: from a BPM perspective, payment transactions are just functions within the logic of a business process, and almost all business services are associated with payment transactions that must be managed online and in real-time. E-Commerce on steroids, if you will. 


\section{Conclusions}

Industry 4.0 leads a clear trend toward a new kind of business processes and e-commerce:

- Decentralized processes with greater decision-making autonomy.

- $\quad$ E-commerce integration at each point, as transaction enabler.

- Real-time control of the automated organizational processes.

- Improved performance and quality of environment-integrated logistic organizational processes.

Although it is still too early to predict the specific impact that these new technologies and tools will have on organizational processes and e-commerce, we can certainly assert that BPM will make no sense without ecommerce, and e-commerce with manual processes has no future either.

\section{Acknowledgements}

This work was partially funded by STIC-AmSud (MOPAIOSIP, code 18-STIC-06) and CONICYT (CCTVal, code PIA/Basal FB0821).

\section{References}

[1] Association of Business Process Management Professionals, BPM Common Body of Knowledge (CBOK), 3 ed. Pensacola, FL: ABPMP, 2013

[2] Germany Trade and Invest (GTAI), Promoted by Federal Ministry for Economic Affairs and Energy in Accordance with a German Parlament Resolution. Berlin, 2016.

[3] R. Geissbauer, J. Vedsø and S. Schrauf, A strategist's guide to industry 4.0, Strategy and Business, vol. Summer 2016, no. 83, 2016.

[4] B. Hitpass, BPM Business Process Management, Fundamentos y Conceptos de Implementación, 4a Edición Actualizada y Ampliada. Santiago: BHH Ltda, 2017.

[5] F. Schönthaler, D. Augenstein and T. Karle, Design and Governance of Collaborative Business Processes in Industry 4.0, In: W. Schmidt, A. Fleischmann, L. Heuser, A. Oberweis, F. Schönthaler, C. Stary, and G. Vossen (Eds.): Proceedings of the Workshop on Cross-organizational and Cross-company BPM (XOC-BPM) co-located with the 17th IEEE Conference on Business Informatics (CBI 2015), Lisbon, Portugal, July 13, 2015. .

[6] P. Tasatanattakool and C. Techapanupreeda, Blockchain: Challenges and Aplications, in Proceedings of the International Conference on Information Networking (ICOIN), Chiang Mai, 2018, pp. 473-475.

[7] V. B. Vukšić, M. P. Bach and A. Popovič, Supporting performance management with business process management and business intelligence: A case analysis of integration and orchestration, International Journal of Information Management, vol. 4, no. 33, pp. 613-619, 2013.

[8] J. Rifkin, The Zero Marginal Cost Society: The Internet of Things, the Collaborative Commons, and the Eclipse of Capitalism. Basingstoke. Hampshire: Palgrave Macmillan, 2014.

[9] W. Yu, F. Liang, X. He, W. Grant Hatcher, C. Lu, J. Lin, and X. Yang. (2017, November) A survey on the edge computing for the internet of things. IEEE Access. [Online]. Available: https://ieeexplore.ieee.org/abstract/docu ment/8123913/ 